\title{
Del monopolio católico al establecimiento del
} pentecostalismo: cambios en el cristianismo latinoamericano desde la segunda mitad del siglo $\mathrm{XX}$

\author{
Fabián Bustamante Olguín ${ }^{1}$ \\ Profesor en ETHICS \\ Universidad de Chile \\ fabianbustamante@uchile.cl \\ Felipe Orellana ${ }^{2}$ \\ Instituto de Sociología \\ Pontificia Universidad Católica de Chile \\ fdorellana@uc.cl
}

Como citar este artigo: Fabián Bustamante Olguín e Felipe Orellana. "Del monopolio católico al establecimiento del pentecostalismo: cambios en el cristianismo latinoamericano desde la segunda mitad del siglo XX”, Intelligere, Revista de História Intelectual, $\mathrm{n}^{\circ}$ 9, pp. 68-97. 2020. Disponível em <http://revistas.usp.br/revistaintelligere>. Acesso em $\mathrm{dd} / \mathrm{mm} /$ aaaa-

Resumen: El presente artículo ofrece un análisis de los cambios en el cristianismo latinoamericano desde la segunda mitad del siglo XX. Interesa demostrar, por un lado, las tensiones al interior del catolicismo latinoamericano, las cuales derivaron en exclusión de diversos sectores dentro de él (en particular la teología de la liberación), y además permitieron, por otro lado, la pérdida de hegemonía de su monopolio en el continente, producto del establecimiento del pentecostalismo, con gran capacidad de adaptación a los contextos culturales latinoamericanos. El artículo se realizó mediante una exhaustiva revisión bibliográfica para generar la reflexión desde un punto de vista sociohistórico.

Palabras clave: Catolicismo, pentecostalismo, cambio religioso, América Latina.

From the Catholic monopoly to the establishment of Pentecostalism: changes in Latin American Christianity since the second half of the 20th century.

\footnotetext{
${ }^{1}$ Magíster en Historia, mención Chile, Universidad de Santiago. Doctor`C en Sociología, Universidad Alberto Hurtado. Profesor en ETHICS, Facultad de Ciencias Físicas y Matemáticas, Universidad de Chile. Correo electrónico: fabianbustamante@uchile.cl. Temas de investigación: Derechas chilenas; Historia del catolicismo político chileno; Historia de América Latina y Sociología histórica.

${ }^{2}$ Doctor en Sociología, Pontificia Universidad Católica de Chile. Profesor del Instituto de Sociología de la Pontificia Universidad Católica de Chile. Correo electrónico: fdorellana@uc.cl. Temas de investigación: Religión y Migración, Pentecostalismo y Globalización, Sociología de la Religión, Teoría Social Clásica y Contemporánea.
} 


\begin{abstract}
This article offers an analysis of the changes in Latin American Christianity since the second half of the 20th century. On the one hand, it is interesting to show the tensions within Latin American Catholicism -which led to the exclusion of various sectors within it (particularly Liberation Theology) — and also allowed, on the other hand, the loss of hegemony of its monopoly on the continent, product of the establishment of Pentecostalism with great capacity to adapt to Latin American cultural contexts-. The article was thought through an exhaustive bibliographic review to generate reflections from a sociohistorical point of view.
\end{abstract}

Keywords: Catholicism, Pentecostalism, religious change, Latin America.

\title{
Introducción
}

El presente escrito analiza los cambios en el cristianismo latinoamericano desde la segunda mitad del siglo XX, a partir de las transformaciones experimentadas en el campo católico, a partir del Concilio Vaticano II (1962-1965), celebrado en Roma, y de la incursión del pentecostalismo, el cual no sólo fragmentó el campo católico (Parker, 1993) sino que erosionó también su monopolio en el continente. Sobre los cambios en el campo católico, cabe señalar que el desafío permanente del catolicismo de mantener un mínimo de unidad doctrinal frente a las diversas opiniones y corrientes dentro de él, se vio en tensión con el Concilio Vaticano II, el cual impulsó un gran debate acerca de las distintas interpretaciones de la esencia, tradición y objetivos de la Iglesia, generándose una lucha de poder dentro de ella. Tal lucha se inició cuando el papa Juan XXIII apuntó hacia una modernización (aggiornamento), con el propósito de comenzar una apertura al mundo e iniciar una relectura de la posición tradicional de la Iglesia frente al proceso creciente de secularización y de disminución de opciones que podía aportar a la sociedad. Ello —en nuestra consideración — permitió, por un lado, que la Iglesia reconociera al campo político como un elemento importante para la evangelización e influencia en la dirección de la sociedad a través de la participación en los procesos políticos en curso y, por otro lado, generó una tensión por la hegemonía de diversos proyectos sociales del catolicismo, ya sea para representar una determinada opción específica de un grupo social o para luchar por la hegemonía de su propio esquema doctrinal (Blancarte, 1996). 
El Concilio Vaticano II se proponía revisar dos asuntos eclesiales relevantes para ese entonces: 1) las tradiciones pastorales y litúrgicas; y 2) emprender una nueva reflexión teológica. Paralelamente a ello se generó un cambio en la estructura y orientación de la Iglesia Católica, dejando atrás la concepción fatalista del "valle de lágrimas" (identificada con el modelo eclesiológico de cristiandad) para abrir una nueva eclesiología autodefinida como "Iglesia, Pueblo de Dios". Eclesiología que, por una parte, definía una nueva identidad permitiendo nuevos ministerios pastorales, nuevas teologías (como por ejemplo la teología de la liberación), colegialidad de los obispos y un nuevo rol del laicado católico; y por otra parte, catalizó los cambios sociales, económicos y políticos generando nuevas tensiones, sobre todo para América Latina. ${ }^{3}$

En relación a esto último, cabe destacar que el peso del contexto latinoamericano acentuó el reconocimiento del pluralismo dentro del campo católico. Situación que ya se venía experimentando años antes, pero que con los contextos históricos como la Revolución Cubana (1959); el apoyo de los Estados Unidos a la Democracia Cristiana en Chile (1964-1970); el golpe militar en Brasil (1964); el asesinato de Ernesto "Che" Guevara en Bolivia (1968) terminaron por politizar al catolicismo latinoamericano. A diferencia de lo que ocurría en Europa y EE.UU, donde la influencia conciliar se concentró en los aspectos teológicos de los documentos (Loaeza, 2008, p.414).

De esta forma se podría decir que, desde un punto de vista políticoideológico, las tensiones internas del Concilio Vaticano II en el ámbito latinoamericano visualizaron diversas corrientes clasificándose — desde nuestra perspectiva - en: 1) las conservadoras-integristas, renuentes a la aplicación de las recomendaciones conciliares; 2) las sociales-cristianas moderadas, que pretendían aplicar las recomendaciones conciliares dentro de los marcos proporcionados por la Iglesia; y 3) las progresistas liberadoras, que enfatizaban el acercamiento teológico pastoral al pueblo y a lo popular.

\footnotetext{
${ }^{3}$ En la historia de la Iglesia Católica siempre han existido tensiones tras un concilio. Tales tensiones, por cierto, se manifiestan en un período de inestabilidad dentro de la Iglesia por el lapso de tiempo en el que se reciben las enseñanzas del concilio en el conjunto de feligreses. Así se podría decir que desde del Concilio de Trento del siglo XVI como el Concilio Vaticano I en el siglo XIX existieron tensiones y problemas. Véase, al respecto, Cunningham, Lawrence, El catolicismo: una introducción, Ediciones AKAL, 2014, p.245
} 
Por otro lado, el pentecostalismo es entendido como un movimiento global, el cual posee la habilidad de adaptarse a diferentes contextos culturales. En el caso de América Latina, el pentecostalismo tiene sus propias especificidades en cada país del continente, pero a su vez presenta elementos comunes que le fortalecen, revisados más abajo, sobre todo en las clases bajas y medias. El pentecostalismo constituye una respuesta a la situación de abandono e incertidumbre para muchos latinoamericanos, sobre todo de clases bajas, que ha dejado el paso desde un modelo social basado en la Hacienda hacia otro neoliberal (Martin, 1998) donde las personas se insertan en solitario en el modelo económico-social, buscando por sus propios medios las alternativas económicas y dejando atrás un modelo económico-social basado en los vínculos de parentesco y en una relación de protección con el hacendado.

En virtud de todo lo anterior, la tesis que proponemos en este artículo es que las corrientes al interior del catolicismo tuvieron en común una matriz integrista, la cual apostaba a una recristianización de la sociedad latinoamericana. Sin embargo, sus lecturas particulares derivaron en una exclusión de otros católicos, y también pavimentando el espacio para el establecimiento del pentecostalismo que aprovechó estas tensiones para dar otro sentido a la experiencia religiosa. Este movimiento religioso se convierte en el transcurso del siglo en una alternativa real y directa para personas en búsqueda de creencias religiosas; la iglesia Católica ya no constituye la opción religiosa monopólica en América latina, sino que el pentecostalismo se convierte en una opción real para mucho latinoamericanos porque permite una relación directa con la divinidad, sin mediadores, y ofrece prácticas de sanación y/o ayuda comunitaria a las personas que adhieren a este movimiento (Orellana, 2012).

$\mathrm{Al}$ interior del catolicismo, las tensiones se concentraron en la discusión sobre la pobreza y sus dos posibles respuestas, a saber: caridad o justicia social. En ese sentido la caridad fue cuestionada por los sectores progresistas liberadores, porque subyace en él un claro ideologismo tradicionalista, defendido por siglos por la Iglesia Católica, que, junto con las respectivas oligarquías latinoamericanas, promovían una forma de preservar el orden social (querido 
por Dios), desigual y con jerarquías naturales, sin modificar siquiera las condiciones sociales de los más pobres. A contrapelo de ello, los católicos progresistas exigían a la autoridad eclesiástica que asumiera una acción pastoral enfocada en la justicia social como objetivo principal.

Ahora bien, con el objetivo de entender estas tensiones del proceso de renovación de la Iglesia Católica, este artículo llevará a cabo un recorrido general del período transitando por los principales caminos que se abrieron en la Iglesia Católica. Se iniciará la partida con el propio Concilio Vaticano II, para luego describir cómo posteriormente influyó en América Latina con la Segunda Conferencia Episcopal de Medellín (1968) y Puebla (1979). Posteriormente seguiremos nuestro recorrido con las consecuencias que tuvo en sectores de la población católica con la teología de la liberación; el diálogo entre cristianismo y marxismo y, por último, las Comunidades Eclesiales de Base (CEB).

\section{La Iglesia Católica como "pueblo de Dios". Concilio Vaticano II}

Los cambios producidos en el catolicismo mundial, como resultado del Concilio Vaticano II, provocaron un impacto dentro del sistema católico. Ello colocaba a la Iglesia en una apertura a los asuntos del mundo, sin quedar indiferente a los cambios socio-políticos acontecidos en Europa y América Latina. Este proceso, en efecto, le permitió superar el "paradigma medieval de la Contrarreforma" para acercar a los creyentes a los dogmas y al culto en un lenguaje más asequible (Patiño, 2006, p.171). Ello tuvo como consecuencia que el proyecto de una Iglesia entendida como "pueblo de Dios" invitaba a una mayor apertura intelectual a las disciplinas seculares (las ciencias sociales) como fuente legítima de conocimiento del mundo. En ese sentido las enseñanzas de la jerarquía eclesiástica, aglutinadas en la encíclica Rerum Novarum del papa León XIII (que conformó lo que se conoce como la Doctrina Social de la Iglesia, e inaugurada a finales del siglo XIX como respuesta a la llamada "cuestión social") fue desplazada por el reconocimiento de la validez de los valores temporales por parte de los documentos conciliares (Loaeza, 2008, p.421). 
Estos cambios en la Iglesia Católica no estuvieron exentos de problemas. Desde ya produjeron una tensión entre el mantenimiento de las estructuras tradicionales pre-concilio, y la apertura teológica de los documentos papales (Estrada, 2009, p.58). En efecto ello se manifestó en tensiones eclesiológicas de dos corrientes enfrentadas que —en palabras de Estrada"hicieron de la relación entre el papa y sus obispos el centro de sus tensiones", expresadas en un sector que defendía la concepción centralista y monárquica del papa, y otros defendían la comunión de todas las Iglesias locales manifestada en la colegialidad de los obispos, siendo uno de los más favorecidos por el concilio (Estrada, 2009, p.60).

En tal concilio, por su parte, se produjo una paradoja que causó a posteriori una crisis de identidad sacerdotal, debido a que se promovía una revalorización de los laicos, considerados por la Iglesia conciliar como sujetos activos, y no meros receptores de los sacramentos (Estrada, 2009, p.77). Al respecto en ningún otro concilio hubo tanto interés por los laicos como en ese entonces, pese a las sospechas de algunos sectores más tradicionales de la cercanía con corrientes provenientes del protestantismo (Estrada, 2009, p.85).

Si bien los laicos tenían una participación ya activa en la Acción Católica, a partir del concilio fueron aún más importantes para la Iglesia por su inserción en un mundo con una creciente secularización y con sociedades cada vez más democráticas, sobre todo después de la Segunda Guerra Mundial. Por ello los laicos tuvieron un rol destacado para diversas corrientes tan diferentes entre sí, como las Comunidades Eclesiales de Base (las cuales analizaremos más adelante), expresión "material" de las tesis de la teología de la liberación; la Renovación Carismática Católica (RCC), surgida en los Estados Unidos en la década del sesenta e influenciada por el protestantismo pentecostal ${ }^{4}$; y el Opus Dei, fundado en 1928 por Josemaría Escrivá de Balaguer en España, de indiscutible ultra conservadurismo, con una tesis que apuntaba a la santificación por medio del trabajo (bien realizado). ${ }^{5}$

\footnotetext{
4 Para un estudio detallado del rol de una comunidad carismática enraizado en sectores populares con un sentido de resistencia a la dictadura militar en Chile, véase al respecto, Bustamante, Fabián, "Historia local de una comunidad carismática católica durante la dictadura militar: Comunidad Dios con Nosotros, 19731983", Persona y Sociedad, Vol. XXV, N³, 2011.

${ }^{5}$ El Opus Dei influyó mucho en las clases altas de Santiago, y formaron a una generación de jóvenes, a partir de la década del sesenta, en las nociones de sacrificio y santificación por medio del trabajo bien
} 
Lo anterior no significó de ninguna manera que los laicos pudiesen actuar de manera autónoma en la sociedad: sólo podían ser los ejecutores de los pronunciamientos realizados por la Iglesia. Ello, en efecto, terminó por generar más de algún conflicto dentro del catolicismo, máxime en la participación de los laicos en movimientos sociales, o en grupos guerrilleros de extrema izquierda (como ocurrirá más adelante en América Latina).

En otros grupos de católicos, por otro lado, rechazaron rotundamente cualquier acercamiento con la modernidad y, por tanto, con las resoluciones del concilio. Tales fueron los sectores conservadores-integristas quienes profesando una ideología tradicionalista- pretendieron mantener el modelo de cristiandad, que postulaba la tesis según la cual la Iglesia debía estar por encima de la sociedad civil, tal como lo hiciera durante la Edad Media en Europa, y en el período colonial español y portugués, respectivamente. Al respecto, en América Latina, por ejemplo, el grupo conocido como Tradición, Familia y Propiedad (TFP), surgido en Brasil en la década del cincuenta y fundado por Plinio Correa de Oliveira (Zanotto, 2010), fue un claro ejemplo de esta tendencia que rechazaba el aggiornamento de la Iglesia, puesto que, desde su perspectiva, ello le daría paso al comunismo, elemento que destruiría bases sociales de la sociedad, a saber: la religión, la familia y la propiedad. Esta organización transnacional tuvo filiales en países como Argentina, Uruguay, Chile, Portugal, Estados Unidos, entre otros países.

En nuestro país, a partir del año 1962, se conformó un grupo filial denominado Fiducia (confianza en latín) en la Universidad Católica de Santiago, publicando la revista homónima (que luego adquirió personalidad jurídica en 1967 denominándose Tradición, Familia y Propiedad), y en el que participaba en su juventud, Jaime Guzmán, intelectual orgánico de la dictadura cívico militar y

realizado, de gran impacto durante la dictadura cívico militar. Al respecto, véase Romero, Javier y Bustamante Olguín, Fabián. "Neoliberalismo poder y religión en Chile". Revista de Investigación Crítica, 5 : 79-100; Bustamante Olguín, Fabián. "La formación de una nueva mentalidad religiosa de la élite empresarial durante la dictadura militar, 1974-1990. El catolicismo empresarial del Opus Dei”. Revista Cultura y Religión 4 (1): 7-20. 
uno de los ideólogo de la Constitución de 1980, que rige actualmente el orden institucional chileno. ${ }^{6}$

De otro lado, un punto significativo de este "giro copernicano" en la Iglesia católica fue sin lugar a dudas sus propulsores: el papa Juan XXIII en 1962 y luego el papa Pablo VI. Este último papa, en su encíclica Populorum progressio (1967), planteaba la tesis de que los pueblos subdesarrollados podían luchar por mejorar sus condiciones de vida, a la vez que realizaba un llamado a las naciones desarrolladas para que actuaran con mayor justicia en sus relaciones con los menos favorecidos. Estos dichos del papa, en efecto, causaron un gran impacto en América Latina, sobre todo en el Conferencia General del Episcopado Latinoamericano (CELAM), reunido en Medellín (1968) (que analizaremos más abajo), y en Puebla (1979), en que —inclusose llegó a plantear la tesis según la cual el subdesarrollo de los países latinoamericanos se debía al desarrollo económico de los países industrializados. Tesis que, por cierto, estuvo influenciada por la Teoría de Dependencia, surgida en la década del sesenta, que planteaba la tesis según el cual el centro domina y explota a la periferia, siendo ésta última víctima del subdesarrollo. Todo ello producto del neocolonialismo, propio del capitalismo liberal, principal factor del atraso económico, tecnológico, social y político de América Latina.

En suma, las consecuencias que traía consigo el subdesarrollo (marginalidad, pobreza, violencia, autoritarismo, etcétera) en América Latina impulsaron a los católicos a comprender la pobreza desde una perspectiva crítica. Ello tuvo como principal resultado la consiguiente conciencia de que la liberación de las estructuras de opresión era la única alternativa para terminar con todos esos males, y así lograr el conjunto de cambios sociales necesarios para hacer más soportable las paupérrimas condiciones de vida de los pobres.

\footnotetext{
${ }^{6}$ Para profundizar sobre el papel que jugó la revista Fiducia en la justificación de la dictadura militar, véase al respecto, Bustamante Olguín, Fabián, "La construcción del enemigo en sus usos lingüísticos del integrismo católico en la justificación del golpe de Estado en Chile. El caso de las revistas Fiducia y Tizona, 1965-1973", Persona y Sociedad, Vol. XXVIII/N¹, enero-abril, 2014.
} 
El acercamiento a la realidad Latinoamericana. Surgimiento de la opción preferencial por los pobres y una nueva teología: La teología de la liberación

La Segunda Asamblea de la Conferencia Episcopal Latinoamericana, celebrada entre agosto y septiembre de 1968, en Medellín, Colombia, aplicó las tesis del concilio Vaticano II a la realidad Latinoamericana, y reformuló la misión de la Iglesia latinoamericana hacia una Iglesia militante estableciendo la opción preferencial por los pobres. En un contexto sociopolítico marcado por la rebelión juvenil en París, de la contracultura, de la crítica social y de la crisis del modelo desarrollista, Medellín, fue la expresión de la "Iglesia como pueblo de Dios", situada en la periferia subdesarrollada y oprimida, que concluye en: 1) Un reconocimiento a la violencia institucionalizada generada por las estructuras de opresión y exclusión; 2) y el protagonismo de los sectores populares latinoamericanos. Dichas conclusiones llevaron a muchos sacerdotes a enfrentar una realidad muy distinta de la que se experimentaba dentro de los monasterios y conventos. Realidad que, en efecto, estaba marcada por la pobreza, violencia y marginación, lo cual permitió una reelaboración de la teología acorde a los "signos de los tiempos", es decir, que exhortara a la necesidad de cambios estructurales. Esto afectaba directamente a los sectores católicos pre-conciliares, puesto que históricamente estaban asociados a las clases dominantes y a la defensa del statu quo. De esta forma surgió la teología de la liberación en Latinoamérica y el Caribe, a partir de la segunda mitad del siglo XX.

En virtud de lo anterior, sus principales representantes fueron los teólogos católicos: Gustavo Gutiérrez, Segundo Galilea, Ernesto Cardenal, Hélder Cámara y Juan Luis Segundo, entre otros; además de los teólogos protestantes como Rubem Alves, Emilio Castro y José Miguez, entre otros. El término, por cierto, se debe al título del libro de Gustavo Gutiérrez, Teología de la Liberación, publicado en 1971 en Lima.

Tales representantes dibujan diferencias entre los distintos representantes de la teología de la liberación. Entonces, por ejemplo, Hélder Cámara fue quien —en 1968 - introduce la noción de "pobre" dentro del lenguaje pastoral, a diferencia de Camilo Torres, por ejemplo, que aludía al concepto de "pueblo". Estos dos conceptos implicaron dos estrategias 
distintas dentro de la teología de la liberación, y que, por tanto, terminó trágicamente para uno de ellos: Camilo Torres fue muerto en combate en 1967. Tal desenlace permite decir que la concepción más radicalizada de la teología de la liberación (la representada por Torres) concluye sin mayor éxito (Corten, 2004, p.301).

En relación a la teología de la liberación (o también se le puede denominar en plural, las teologías de la liberación), ésta postula que el sujeto histórico de la Iglesia no es el creyente, sino el pueblo oprimido, un pueblo que se organiza para idear las luchas por el cambio social. Bajo esta perspectiva, la evangelización sería un proceso crítico (opuesto a las prácticas tradicionales, la cual no admitía discusión), lo que se expresaría en una "opción preferencial por los pobres". En tal sentido el eje de la evangelización sería la construcción del Reino de Dios de forma anticipada en la tierra articulada en los valores de solidaridad y confraternidad humana (Castro Gómez, 2008:32). De este modo la Iglesia debía encarnarse en la realidad social, política y económica de América Latina, una encarnación de los pobres y postergados. Es por esta razón que buena parte del clero de base se unió a los movimientos sociales y partidos políticos de izquierda, generando una oposición por estos planteamientos debido a su cercanía con el marxismo en los sectores conservadores. En este aspecto los sectores conservadores-integristas y algunos socialcristianos moderados (como el Obispo Alfonso López Trujillo, el jesuita Roger Veckemans, Kloppenburg, entre otros) acusaron duramente a la teología de la liberación de infiltración marxista al interior de la Iglesia llegando incluso- a amonestar a dos de sus principales representantes como Gustavo Gutiérrez y Leonardo Boff. Posteriormente estas amonestaciones sirvieron como pretexto durante la década de los ochenta para la elaboración de un documento del Vaticano, con la firma del cardenal Joseph Ratzinger (Benedicto XVI posteriormente), titulado de la Instrucción de la Sagrada Congregación de la Doctrina de la Fe sobre algunos aspectos de la teología de la liberación (conocida también como la Carta Ratzinger), publicada en agosto de 1984, al que se le realizó un exhaustivo inventario de las principales objeciones a la teología de la liberación desde el punto de vista eclesiástico. 
En virtud de lo anterior, por otro lado, cabe destacar que el inicio del pontificado de Juan Pablo II (en 1978) estuvo marcado por su acción centralizadora para evitar la división de la Iglesia. Ello se tradujo en diversas visitas a América Latina (región a futuro importante para el destino de la Iglesia por la gran cantidad de fieles), enfatizando en la "opción por los pobres y no en la lucha de clases". ${ }^{7}$ En esa línea el trato humillante de Juan Pablo II hacia Ernesto Cardenal, Ministro de Cultura del gobierno sandinista en Nicaragua, no era algo casual. La imagen de Juan Pablo II forzando a Cardenal a arrodillarse ante él, en su visita en 1983 a ese país, era una clara señal de tensión entre dos visiones eclesiológicas contrapuestas. Sin embargo, a contrapelo, el papa realiza una visita a Chile en 1987, legitimando al dictador Augusto Pinochet, otro furibundo anticomunista al igual que el papa.

Lo señalado arriba, por cierto, estuvo en plena correspondencia con la tesis de fondo de Juan Pablo II de preservar el poder de la Iglesia católica en nuestro continente. Tal tesis, en efecto, fue el resultado de una variable externa: la actitud de Estados Unidos que consideró (sobre todo en los gobiernos republicanos de Richard Nixon y Ronald Reegan) que la Iglesia católica era cómplice de la Unión Soviética por el surgimiento en su seno de la teología de la liberación, lo cual abrió el camino a las Iglesias evangélicas estadounidenses a que se establecieran en diversas ciudades latinoamericanas expandiendo la llamada "teología de la prosperidad", que, en términos generales, resultó ser una opción preferencial para los ricos. Frente a ello, Juan Pablo II se reunió con Reegan (dos anticomunistas reconocidos) en 1982 para encontrar un compromiso con los Estados Unidos (Kourliandsky, 2013, p.60). Tal reunión consolidó, por un lado, una alianza estratégica entre Juan Pablo II y Ronald Reegan, quienes trabajaron para poner fin a la Unión Soviética; y por otro lado, el nombramiento de obispos conservadores por parte del papa en el mundo católico. En tal sentido es interesante destacar el ascenso del Opus Dei, el cual alcanzó el carácter de prelatura personal en 1982, evidenciando el carácter conservador de la cúpula romana. Ello como consecuencia del giro restaurador del pontificado de Juan Pablo II para contrarrestar a los sectores progresistas, particularmente a la teología de la liberación. Ni siquiera los jesuitas -

7 Al respecto, cabe señalar que Juan Pablo II había vivido tras la "cortina de hierro", en una Iglesia del Silencio, en Polonia, una época en que los regímenes socialistas proscribían a los católicos. 
digamos, entre paréntesis—, habían logrado semejante posición dentro de la Iglesia católica teniendo muchos años más de existencia.

Cabe señalar, por último, que la Tercera Conferencia Episcopal (celebrada en la ciudad mexicana de Puebla en 1979), y Juan Pablo II, hicieron lo imposible para silenciar a los sectores progresistas (ligados a la teología de la liberación), intentando seguir las conclusiones de Medellín, pero con las “correctas" interpretaciones (citado en Blancarte, 1992, p.283). Pese a ello, tal conferencia oficializó la "opción preferencial por los pobres", desde una perspectiva institucional, que evidenció — por cierto - un intento de orientar las tesis sostenidas sobre la pobreza de la teología de la liberación, la cual ya había comenzado a rebasar el control de la jerarquía católica que tenía sobre la estructura eclesial. La participación de los católicos, desde el punto de vista institucional, debía estar encauzado desde las enseñanzas de la Iglesia, y no desde otras perspectivas "ateas" o "materialistas" (léase marxismo).

Otra preocupación para la jerarquía vaticana fue el ascenso del Frente Sandinista de Liberación Nacional (FSLN), que derrocó a la dictadura patriarcal de los Somoza en Nicaragua. Téngase en cuenta que los cristianos habían desempeñado un papel importante en el derrocamiento de la dictadura. Ahí aparece el señalado arriba Ernesto Cardenal junto a los guerrilleros del FSLN oficiando misas para levantar la moral de los combatientes.

Agreguemos, por último, que el papa Juan Pablo II posteriormente- sintetizará las ideas sobre la pobreza en el llamado Compendio de la Doctrina Social de la Iglesia (2004), como una forma de delimitar y evitar los “excesos” interpretativos de la teología de la liberación.

Pese a las ofensivas del Vaticano y de Juan Pablo II, en el contexto del año 2000, en fin, la teología de la liberación se convirtió en el pilar ideológico de algunos de los presidentes de Venezuela, Bolivia, Nicaragua, Ecuador y Paraguay, en el marco del "giro hacia la izquierda" en los países de América del Sur y Central, lo cual refleja la importancia de esta corriente dentro del catolicismo en la configuración política de nuestro continente. Tal vez sea este el motivo del por qué El Vaticano no declara herética esta doctrina porque da 
cuenta de su popularidad, y además mantiene la hegemonía católica frente al rápido ascenso del pentecostalismo en la región.

\section{Cristianismo y marxismo}

Un aspecto a destacar de las tensiones dentro del catolicismo es el diálogo cristiano-marxista. Tal diálogo, en efecto, fue por el aggiornamento de la Iglesia católica, sumado a las tesis de la Segunda Conferencia Episcopal de Medellín y la flexibilización del dogma estalinista en el marxismo. En ese marco, este diálogo (que por cierto superó la clásica expresión de Marx sobre la religión como "opio del pueblo") se generó por primera vez en Francia con las tesis del filósofo marxista Roger Garaudy y el jesuita Jean Yves Calvez, cimentado paralelamente en la experiencia de los "curas obreros" en los suburbios franceses. También se podrían destacar otros tres neomarxistas, abiertos al diálogo con los sectores cristianos: el alemán Ernest Bloch y el italiano Antonio Gramsci.

El acercamiento entre cristianos y marxistas, en efecto, tuvo como consecuencia principal una división fuerte del catolicismo latinoamericanos, y fue mirado con preocupación, como era lógico, por el ala conservadora del catolicismo, el cual consideraba una herejía establecer lazos con el marxismo ateo, "intrínsecamente perverso", según lo dicho por el papa Pio XI. En efecto, el papa Pío XII, en 1949, dictó la histórica proclama que imponía pena de excomunión a todos aquellos católicos que apoyaran al comunismo.

En virtud de lo anterior, en Chile, el año decisivo para este diálogo fue 1965, año en que ocurrieron dos acontecimientos importantes como respuesta a la ofensiva del gobierno demócrata cristiano de Eduardo Frei Montalva (1964-1970) expresada en la consigna "religión versus marxismo". ${ }^{8}$ En primer lugar, la manifestación entre los meses de abril y mayo que unió a cristianos y marxistas para condenar la invasión imperialista estadounidense en la República Dominicana, que derrocó al presidente Juan Bosch y dio su apoyo al

\footnotetext{
8 Sin embargo, hubo una expresión previa en Chile de este "diálogo cristiano-marxista" en el grupo Germen, primera expresión de una "iglesia de los pobres" -según lo afirma Maximiliano Salinas- fundado por Clotario Blest en 1933. "En 1933 el grupo Germen -añade Salinas- expresaba su decisión de romper definitiva y radicalmente los torpes lazos que inconscientemente han amarrado a los católicos al criminal régimen capitalista en que vivimos". Véase, al respecto, Salinas, Maximiliano, Historia del Pueblo de Dios en Chile. La Evolución del Cristianismo desde la perspectiva de los pobres. Ediciones Rehue, Santiago, 1987, p.235.
} 
régimen represivo de Joaquín Balaguer. Y en segundo lugar, la publicación del ensayo El desarrollo de la nueva sociedad en América Latina, de los militantes demócratacristianos Jacques Chonchol y Julio Silva Solar. Tal ensayo, en efecto, planteó "una vía no capitalista de desarrollo", contribuyendo a forjar un polo crítico al interior del Partido Demócrata Cristiano, que por ese entonces estaba en el gobierno (Amorós: 2005, p.108).

Posteriormente a estos acontecimientos se originó el Movimiento "Iglesia Joven" originado a partir de la "toma" de la Catedral de Santiago en 1968, por parte de sacerdotes y laicos, bajo la consigna de una "Iglesia junto al pueblo y su lucha" (Salinas, 1987, p.239). Luego esta experiencia derivó en la conformación del grupo "Cristianos por el Socialismo" (CpS en adelante), resultado de un encuentro celebrado en abril de 1971, que culminó con la "declaración de los 80" en el cual manifestaban su adhesión a un socialismo despojado de todo marxismo dogmático. Agréguese, además, un centenar de sacerdotes se habían reunido con Fidel Castro (quien por esos días visitaba el Chile de la Unidad Popular), el 29 de noviembre de 1971, en los jardines de la Embajada de Cuba en Santiago (Amorós, 2005, pp.115-116). ${ }^{9}$ Posteriormente CpS organizó un congreso a nivel continental en el cual participaron cristianoscatólicos y protestantes (tanto latinoamericanos como europeos), reunidos en abril de 1972 en Santiago, buscando su integración en el proceso de construcción de un Chile socialista, apoyando abiertamente al gobierno del presidente Salvador Allende (1970-1973).

Todo lo anterior contrastaba con la posición de la jerarquía católica, liderada por el cardenal Raúl Silva Henríquez, de posición socialcristiana moderada, acusando a CpS de causar división dentro de la Iglesia. Del mismo modo —aunque más radical— los católicos conservadores integristas se refirieron a los CsP como una "infiltración marxista" en la Iglesia (Bustamante Olguín, 2014). Lo interesante de ello es que este último sector apoyó el golpe militar de 1973, condenando abiertamente a los CpS quienes muchos de ellos terminaron exiliados, torturados y asesinados por la dictadura cívico militar. ${ }^{10}$

\footnotetext{
9 Posteriormente, Fidel Castro invitó a una delegación de CpS para visitar Cuba en marzo de 1972. $10 \mathrm{Al}$ respecto, es interesante destacar el libro de Teresa Donoso Loero, periodista, activista política y militante del Partido Demócrata Cristiano, titulado Los Cristianos por el Socialismo en Chile, publicado en 1975, en un intento de desacreditar el diálogo cristiano- marxista que tuvo como resultado la experiencia
} 
En el resto del continente, en tanto, religiosos y creyentes se radicalizaron y se agruparon en torno a grupos comprometidos para luchar contra la pobreza y el subdesarrollo como el Grupo Guacolda en Colombia, la Oficina Nacional de Investigaciones Sociales en Perú, Sacerdotes para el Tercer Mundo en Argentina.

A todo lo dicho hay que agregar, por último, que la teología de la liberación —y de acuerdo a los propios problemas del subdesarrollo señalados arriba-, aceptó algunos conceptos del marxismo, a saber: el determinismo económico, las relaciones estructura-superestructura, la lucha de clases y plusvalía, mientras que el materialismo dialéctico fue rechazado por estar a contrapelo del aspecto metafísico del dogma católico. Con respecto a la lucha de clases, si bien privilegió los métodos pacíficos, la teología de la liberación no descartó la violencia bajo ciertas circunstancias que implicaran su uso, aunque en ciertos casos algunos se radicalizaron dejando su sotana para enrolarse a la guerrilla.

Cabe decir que uno de los casos emblemáticos fue el mencionado Camilo Torres Restrepo en el Ejército de Liberación Nacional -ELN- (guerrilla de origen guevarista surgida en la década del sesenta en Colombia), quien murió en combate en 1966 y luego fue convertido, en palabras de José del Pozo, "en mártir de la izquierda católica" (Del Pozo, 2009, p.224). Dentro de esa misma guerrilla se encontraban entre sus líderes otros ex sacerdotes: Domingo Laín, español, y Manuel Pérez — también español- que incluso llegó a ser jefe del ELN hasta su muerte en 1997.

\section{Comunidades eclesiales de base}

Se podría sostener que las Comunidades Eclesiales de Base (CEB en adelante) surgieron mucho antes de la conceptualización acuñada en la Segunda Conferencia Episcopal de Medellín. En ese sentido, las CEB (también conocidas como Comunidades Cristianas Base - CCB $)^{11}$-, se conformaron por

de las CpS. Véase, Donoso Loero, María, Los Cristianos por el Socialismo en Chile, Santiago, Editorial Vaitea, 1975.

${ }^{11}$ Sobre este punto cabe señalar que en Chile durante la dictadura cívico militar, las CEB y CCB tuvieron conceptualmente definiciones distintas. Si bien es cierto que ambos términos resultaron sinónimos dentro del mundo católico, las CEB se definieron como la Iglesia que se hacía presente en la base representada por la parroquia, mientras que la CCB se definía como el espacio íntimo donde se compartía la vida y la fe, pero en un lugar mucho más reducido (que puede ser, por ejemplo, la casa de algún laico miembro de 
la iniciativa de los laicos ante la escasez de sacerdotes que sufría la Iglesia católica en el noreste de Brasil durante la década del 50’. Estas comunidades correspondían a pequeños grupos de fieles católicos formados en los barrios marginales de las grandes ciudades latinoamericanas y en zonas rurales, dedicados tanto a la lectura de la Biblia, a realizar oración, a la ayuda pastoral a los más pobres como también a la acción política.

Por otra parte, hay que hacer notar que las CEB tuvieron en la teología de la liberación una ideología que justificaba su accionar eclesial y político. Esto permitió identificar a estas comunidades como Iglesia "Popular", con una clara orientación de opción por los pobres, aglutinando a los sectores progresistas dentro del clero y los laicos.

En este marco descrito las CEB se podrían definir como grupos pequeños, por lo que estaban integradas por 15 a 20 personas, entre los que se incluían sacerdotes, monjas y laicos, surgiendo, principalmente, en Brasil, y posteriormente en Perú, Chile, Nicaragua, El Salvador, y en el resto de América Latina, a partir de la década del sesenta y setenta. Tales comunidades, por cierto, tuvieron mucho protagonismo en la defensa de los DD.HH ante las cruentas dictaduras militares que azotaban a la región. Al respecto el caso brasileño constituye un referente del apoyo de las CEB a los DD.HH, sobre todo durante la dictadura militar, convirtiéndose en una voz de protesta ante la represión. Téngase en cuenta que las CEB se transformaron en un movimiento social de suma importancia para la vuelta a la democracia principalmente en Brasil y Chile.

En este último país, por cierto, las CEB reconstruyeron el tejido social popular en los primeros años de la dictadura, cuestión que más adelante va a ser significativo para la protesta social que tuvo su momento de explosión en las denominadas Protestas Nacionales de 1983 y 1984 para derrocar a la dictadura cívico militar, encabezada por el General Pinochet (Garcés y De La Maza, 1985; Cherkashin, 2000).

la parroquia). Al respecto véase, David Fernández, La Iglesia que resistió a Pinochet: historia, desde la fuente oral, del Chile que no puede olvidarse, Editorial IEPALA, Madrid, 1999. En la misma línea, también véase, Bustamante Olguín, Fabián. "Historia local de una comunidad carismática católica durante la dictadura militar: Comunidad Dios con Nosotros, 1973-1983”, Persona y Sociedad, Vol. XXV, N³, 2011. 
En virtud de lo anterior, podríamos agregar, a modo de hipótesis, que el trabajo realizado en la base social por las CEB chilenas permitió crear la idea de "concertación", incluso mucho antes que enunciaran como idea las elites políticas. Tal "concertación", bloque histórico entre el centro y la izquierda chilena, no se hubiera construido, sin antes haberse configurado en la base social. La práctica cotidiana de estas CEB, a partir de 1973 en adelante, ayudó a que los "antiguos enemigos" políticos (léase comunistas y demócrata cristianos) compartieran espacios, proyectos, con una cierta lógica en común, a saber: luchar contra de la dictadura.

\section{Pentecostalismo y Globalización}

Los orígenes del pentecostalismo usualmente se identifican a inicios del siglo XX en los EEUU. Pero este avivamiento sucedió simultáneamente en otros lugares como la India o el África sub-sahariana (Beyer, 2007). Desde las primeras décadas del pasado siglo, algunos misioneros pentecostales se movieron a diferentes partes del mundo, pero algunas características de este movimiento - la presencia del Espíritu Santo, hablar en lenguas, prácticas de sanación de enfermedades y exorcizar demonios - se encontraban ya presentes en diferentes países antes del momento originario identificado (Miller y Yamamori, 2007). Según Beyer (2007) los orígenes americanos del movimiento fueron una fuente de identidad, en vez de un lugar original desde el cual el pentecostalismo se expandió alrededor del planeta. En efecto, en diferentes lugares la gente tuvo alguna información sobre el pentecostalismo y ellos adaptaron este movimiento a sus contextos locales. Por estas razones, "el pentecostalismo creció a nivel mundial como una serie de variaciones de un mismo tema" (Beyer, 2007, p.450). En otras palabras, un componente clave del pentecostalismo, desde sus orígenes, ha sido su carácter global.

Por una parte, Wilkinson (2008) argumenta que el pentecostalismo es usualmente relacionado con la modernización en lugar de la globalización. En su visión, algunos enfoques han interpretado que este movimiento surgió en los procesos modernizadores para lidiar con los problemas que otros movimientos religiosos no podían resolver —religión entendida en este contexto como una respuesta a la secularización-. Sin embargo, otros 
enfoques han afirmado que el pentecostalismo es un fenómeno global que es formado por el contexto local y "existe a través del mundo sin ninguna influencia americana" (Wilkinson, 2008, p.106). Por otra parte, Adogame (2010) argumenta que el pentecostalismo y su expansión mundial y desarrollo son fenómenos sociales relacionados directamente con la globalización. Más aún, afirma que "la aplicación de la globalización al pentecostalismo se refiere a su expansión geográfica, su crecimiento demográfico y su influencia cultural" (Adogame, 2010, p.505). En este sentido, Adogame (2010) plantea que el pentecostalismo y la globalización han estado relacionados desde los orígenes de este movimiento religioso.

Como un ejemplo del enfoque de la modernización, Lalive (1969) especifica que el pentecostalismo es exitoso entre los pobres porque es una fuente de certidumbre contra la anomia. Según Lalive (1969) en los sectores pobres de las zonas rurales y urbanas en Chile, la población puede encontrar un fuerte apoyo en la comunidad pentecostal. No obstante, siguiendo a Adogame (2010), el pentecostalismo puede ser visto como una respuesta a la modernización en sociedades en desarrollo, pero está directamente vinculado a la globalización "como un producto o consecuencia de esta" (p. 505). Esta discusión nos lleva a interrogar si el pentecostalismo es un fenómeno global o local. Primero, se puede afirmar que los orígenes de este movimiento religiosos son globales -aunque usualmente se le identifica con un solo lugar: los EEUU_, pero, segundo, este movimiento adopta las formas culturales particulares de los lugares donde se sitúa. En este sentido, Miller y Yamamori (2007) han identificado que el "pentecostalismo es un movimiento altamente adaptable y típicamente incorpora las formas culturales de un contexto local" (p. 20).

Producto de su expansión mundial en el siglo XX el pentecostalismo es considerado como el movimiento religioso más exitoso de ese siglo (Jenkins, 2007). Una posible explicación de este éxito es que este movimiento promueve un modelo de religión en el cual las personas tienen una fuerte presencia porque las Escrituras pueden ser interpretados por cualquiera, sin un mediador entre ellos y Dios (Orellana, 2012). Por ejemplo, en relación con las explicaciones a la exitosa expansión del pentecostalismo a nivel mundial, Miller 
y Yamamori (2007) han argumentado que este éxito puede ser entendido desde una interpretación funcional o sustantiva. La primera está en relación con las consecuencias de la modernización, por ejemplo, el costo social de la migración del campo a la ciudad, y la segunda interpretación tiene relación con la búsqueda de sentido en un contexto cultural. En adición, según Robbins (2004), en la literatura de pentecostalismo es posible identificar dos tendencias: primero, algunas tendencias destacan la homogeneidad del pentecostalismo a nivel mundial y segundo, otras perspectivas manifiestan la fuerte capacidad de este movimiento para adaptarse a los contextos locales. El pentecostalismo es entendido "por teorías que destacan procesos de dominación cultural occidental y homogeneización [por un lado] y por teorías que enfatizan el poder transformador de la apropiación indígena y diferenciación [por otro]" (Robbins, 2004, p.118).

En este sentido surge la pregunta ¿qué es global y qué local en el pentecostalismo? De acuerdo con Adogame (2010) y Orellana (2012) los pentecostales pueden ser reconocidos porque enfatizan un renacimiento (a través de un bautismo en el espíritu), hablan en lenguas (glosolalia), identifican eventos futuros (profecía) y usan cultos emocionales y exuberantes. Estos son elementos comunes que pueden ser evidenciados en diferentes lugares con afinidades en ideología, liturgia, organización y ética (Adogame, 2010). Esta tendencia del pentecostalismo, según Lehmann (2009), se puede pensar como ejemplo de un movimiento contraintuitivo, porque el pentecostalismo como fenómeno cultural debe situarse en los respectivos contextos culturales, en lugar de expandirse como un movimiento homogéneo a través del planeta. Pero "la unidad del modelo es el producto de un siglo de experimentación y comunicación: se observa en estilos de prédicas, en un mensaje común sobre las tentaciones del mundo y la salvación a través de la aceptación de Jesús" (Lehmann, 2009, p.417). No obstante, en la visión de Adogame (2010) los pentecostales "deben ser vistos como un difuso movimiento global y no como una centralizada, interna organización" (p. 500). Adicionalmente, mientras los pentecostales pueden compartir ciertos elementos —en un sentido global—al mismo tiempo los pentecostales tienen autonomía religiosa. Pueden desarrollar sus propias formas culturales según el respectivo contexto cultural. Como 
Lehmann (2009) argumenta, las comunidades pentecostales adoptan simbolismos de la cultura local, como nombres de diablos o espíritus locales (Brasil y África son ejemplos de esta apropiación local). En otros términos, como Robbins (2004) ha notado "la cristiandad Pentecostal-carismática es altamente moldeable y rápida de identificar porque es extraordinariamente abierta a realizar expresiones sincréticas con formas indígenas de culto" (p. 126).

\section{Características Culturales del Pentecostalismo en América Latina}

Por otra parte, ¿qué formas tiene el pentecostalismo en un contexto cultural delimitado? La anterior discusión muestra como el pentecostalismo se adapta en el contexto de la globalización. En este sentido, la discusión sobre características homogéneas o particulares de este movimiento se pueden identificar en América Latina. Esta región es parte del Sur Global que ha surgido a través del mundo en el siglo XX (Jenkins, 2007). Por un lado, como un ejemplo de las características particulares del pentecostalismo en América Latina "una cultura pentecostal unificada no puede ser asumida" (Cleary, 1999, p.135), porque en los países de esta región existen diferencias en aspectos relacionados a la vida religiosa, como educación bíblica, servicios de rehabilitación o sistemas educacionales para los laicos (Cleary, 1999). Más aún, según Freston (1998), "[el] pentecostalismo es segmentado. Si, en el catolicismo, todos los caminos llevan a Roma, en [el] pentecostalismo muchos terminan donde comienzan: en un suburbio de Rio o en una villa guatemalteca" (p. 338). Adicionalmente, el pentecostalismo muestra diferencias entre los países de América Latina. Por ejemplo, las Iglesias históricas de Brasil - como la Asamblea de Dios- tiene presencia entre diferentes clases sociales; pero en Chile, las iglesias pentecostales tienen más miembros de las clases bajas (Freston, 1998). Más aún, “[El] pentecostalismo chileno es acentuadamente nacional en origen" (Freston, 1998, p.343) y sus fuentes son dos iglesias que son divisiones de la original Iglesia Metodista Nacional de 1909. En Chile, este movimiento religioso tiene menos tendencias a fenómenos como la Iglesia Universal Brasileña o el neo-pentecostalismo (que es está muy presente en América Central) (Freston, 1998). 
En relación con otros países de la región "[El] pentecostalismo [chileno] es más nacional que en cualquier otra parte de América Latina" (Freston, 1998, p.343). El caso peruano es diferente porque en este país el "pentecostalismo es una minoría dentro del protestantismo" (Freston, 1998, p.343) y la Asamblea de Dios tiene una fuerte presencia debido al trabajo misionero americano. Otra forma nacional de pentecostalismo es El Salvador en el cual dos iglesias principales (Asamblea de Dios e Iglesia de Dios) tienen la mayor influencia, y muchos grupos neo-pentecostales tienen presencia también (Freston, 1998). En el caso de Argentina, Míguez (1999) ha argumentado que el crecimiento del pentecostalismo está basado en la búsqueda religiosa de personas afectadas por problemas; pero el pentecostalismo influencia otros asuntos —no sólo religiosos—. Por ejemplo, entre sus entrevistados Míguez (1999) encontró que la religión ha dado, a aquellos afectados por problemas, respuestas a preguntas trascendentales y una comunidad que los apoya en aspectos económicos o en la búsqueda de trabajo.

De acuerdo con Míguez (1999), el problema con algunas explicaciones sobre el crecimiento del pentecostalismo en América Latina - por ejemplo, Lalive (1969) - es que vinculan este movimiento con procesos socioeconómicos de la modernización. Pero, estas explicaciones no se enfocan en las creencias religiosas de las personas. En adición, la pluralización y privatización de la religión en Argentina ha causado que las personas exploren las opciones religiosas por si mismas, en lugar de usar un modelo religioso heredado que resolvería sus necesidades. En otras palabras, Míguez (1999) enfatiza que las explicaciones a la expansión pentecostal en la región deben considerar las creencias personales y las prácticas de las personas y no sólo los aspectos sociales del pentecostalismo. Este puede ser un útil recurso para analizar la presencia pentecostal en América Latina porque es posible entender los elementos que este movimiento provee a personas que están buscando un grupo religioso. Al mismo tiempo, si comprendemos los elementos centrales que las personas consideran para unirse al pentecostalismo, es posible diferenciar este movimiento dentro del campo religioso de la región.

En relación con el crecimiento pentecostal, algunos elementos de la perspectiva homogeneizadora pueden ser utilizados. Dentro de la región hay 
evidencia de formas particulares e historias nacionales del pentecostalismo que son ejemplos de rasgos locales, pero al mismo tiempo, algunos elementos culturales en América Latina son compartidos entre diferentes países — como la presencia de la Iglesia Católica - y desde estos el pentecostalismo se ha expandido como un importante movimiento religioso. Esto, "ha efectivamente erosionado el monopolio cultural del Catolicismo que persistía en los territorios españoles del Nuevo Mundo mucho después de la separación formal de iglesia y estado, y finalmente ha acontecido en una era de creciente pluralismo religioso" (Martin, 1998, p.108). En la visión de Martin (1998), el pentecostalismo latinoamericano presenta algunas características comunes; por ejemplo, este movimiento comparte importantes continuidades con la cultura tradicional que ha sido amenazada por la Iglesia Católica desde el período de la Conquista. Esta conexión con los elementos culturales tradicionales puede observarse en los exuberantes cultos pentecostales. En adición, América Latina sería una región aún "encantada" porque sólo unas elites intelectuales habrían conocido las ideas de la Ilustración, mientras la mayoría de la población estaría en contacto con prácticas mágicas y tradicionales. Más aún, Martin (1998) propone una interesante interpretación para el crecimiento pentecostal, en su visión esto se puede relacionar con el hecho de que América Latina sufrió un fuerte cambio desde una situación pre-moderna a una condición postmoderna. En esta región

Un sistema cultural y social basado en la relación patrón[inquilino] donde los pobres no tenían presencia política y eran definidos socialmente por sus roles adscritos, ha cambiado rápidamente a un sistema en que las oportunidades y los costos caen cada vez más en los individuos como unidades atomizadas a [nivel] social y económico (Martin, 1998, p.129).

Este cambio ha implicado importantes consecuencias; por ejemplo, significantes segmentos de la población latinoamericana viven en condiciones precarias. En esta región, el industrialismo fue desarrollado en un período tardío —en relación a EEUU o Europa - y la situación actual muestra la presencia de una economía post-industrial. Los antiguos vínculos patróninquilino (donde la Hacienda es la unidad en este sistema pre-moderno) han sido modificados por un sujeto individualizado con actitudes de emprendimiento hacia el trabajo (Martin, 1998). Estos cambios han afectado a los pobres que han sido desplazados de las antiguas estructuras económicas, 
deben moverse del campo a la ciudad y a causa de esto se hallan ante un inseguro estilo de vida. En este contexto, "el nuevo protestantismo se ve como una forma de resistencia a precisamente esos aspectos de la condición postmoderna... [como] la fluidez, la incertidumbre, las contradicciones y excesos" (Martin, 1998, p.127).

Segundo, dentro de estas tendencias homogeneizadoras, una explicación común al exitoso crecimiento del pentecostalismo es que este movimiento es un recurso de empoderamiento para los pobres (Chesnut, 2003). En palabras de Chesnut (2003) "numerosos estudios...han mostrado que los pentecostales latinoamericanos son pobres, [que] tienden a tener menos ingresos y menos educación que la población general” (p. 41). El pentecostalismo se ha expandido exitosamente porque ofrece soluciones, como sanación o refugio, a personas que sufren de pobreza, soledad, alcoholismo, etc. En este sentido, Martin (1998) y Chesnut (2003) han afirmado que el pentecostalismo es importante porque enfrenta los problemas de las personas ubicadas en las más débiles posiciones en los países latinoamericanos.

Pero ¿se puede argumentar que la expansión pentecostal está relacionada con la falta de recursos de muchos latinoamericanos? $\mathrm{O}$ ¿tiene vitalidad el pentecostalismo principalmente porque es una religión de los pobres? Considerando el hecho de que muchos pobres encuentran soluciones a sus problemas en el pentecostalismo (Chesnut, 2003), ¿isignifica esto que el pentecostalismo tiene presencia solo en los sectores pobres?, ¿qué elementos debemos considerar para entender el pentecostalismo en América Latina? La composición social del pentecostalismo ha cambiado (Miller y Yamamori, 2007) porque en las primeras décadas del siglo XX se difundió entre las clases bajas, "pero en las últimas décadas en particular, [el] pentecostalismo ha atraído una nueva clase de personas más acomodadas y educadas" (Miller y Yamamori, 2007, p.21).

Por ejemplo, en la sociedad chilena, los últimos 20 años han significado importantes cambios en los estándares de vida, una percepción general positiva de la democracia, acceso a educación y bienes culturales, un descenso en niveles de pobreza, entre otros (Fediakova, 2014). Estos cambios sociales "también han afectado a la población evangélica" (Fediakova, 2014, p.110), 
porque los jóvenes evangélicos (personas de menos de 30 años) han tenido acceso a la educación universitaria en niveles mayores que las generaciones mayores. Estos altos niveles de educación se han traducido en que los jóvenes evangélicos tienen una mejor condición socioeconómica y, al mismo tiempo, opiniones más liberales en temas tradicionales. La educación universitaria es el elemento clave para entender la posición de las generaciones jóvenes en temas como el aborto o la política. Estas posiciones son ejemplos de "diferencias en temas ético-sociales y actitudes entre generaciones [por] el creciente acceso a la universidad de jóvenes de sectores pobres” (Fediakova, 2014, p.114). Según los datos de Fediakova (2014) no es posible argumentar que los evangélicos -la autora usa esta categoría e incluye en ella otras iglesias como pentecostales y neo-pentecostales- están presentes principalmente entre los pobres. Los evangélicos, mediante el acceso a la educación y mejores trabajos, han mejorado su condición social. La educación universitaria no sólo ha significado puntos de vista más liberales entre las generaciones más jóvenes, esta ha producido una nueva actitud acerca de figuras tradicionales de las comunidades evangélicas.

Generalmente, las iglesias pentecostales fueron asociadas con sectores pobres, pero estas iglesias han cambiado sus miembros (Droogers, 1998). Una explicación de esto "es que [el] pentecostalismo promueve movilidad social ascendente" (Droogers, 1998, p.9), por lo tanto, es posible encontrar personas de clase media y alta entre los pentecostales. Más aún, se puede cuestionar si los pobres son la principal fuente de los creyentes pentecostales porque "[ellos] pertenecen a una variedad de estrato sociales. Junto a esto, personas del mismo estrato social no necesariamente tienen las mismas preferencias religiosas" (Droogers, 2008, p.115).

Por otra parte, un rasgo cultural latinoamericano como el machismo tiene una particular relación con el pentecostalismo. El machismo es un tipo de relación entre hombres y mujeres que enfatiza la importancia de aquellos y la sumisión de ellas (Slootweg, 1998). En efecto, "las mujeres son consideradas inferiores y seres pasivos. Ellas deben seguir a los hombres en todo, obedecerlos, respetarlos" (Slootweg, 1998, p.59). En línea con esto, los 
hombres tienen una actitud agresiva y viril, tienen una libertad sexual que es prohibida a las mujeres, debido a que este tipo de masculinidad se asocia a la promiscuidad sexual. En este contexto, el pentecostalismo ofrece una nueva relación entre hombres y mujeres porque enfatiza la importancia de la familia y las responsabilidades de los hombres hacia su mujer y los hijos (Slootweg, 1998). Es así como, de acuerdo con las mujeres pentecostales entrevistadas por Slootweg (1998) en Iquique, Chile, la conversión de sus maridos al pentecostalismo ha implicado un descenso del machismo. Esto se puede apreciar en que "la responsabilidad por la casa (incluyendo los aspectos económicos) se comparte, hay un cierto grado de protección contra la infidelidad y los abusos físicos causados por el alcohol se eliminan de igual manera" (Slootweg, 1998, p.61).

Adicionalmente, Brusco (1993) ha encontrado evidencia similar en Colombia, en su visión el pentecostalismo es un poderoso antídoto contra el machismo porque "la personalidad machista y el rol del hombre definido por el protestantismo evangélico son diametralmente opuestos" (Brusco, 1993, p.148). La conversión al pentecostalismo produce una disposición hacia el hogar y la familia, en lugar de actividades comunes en el comportamiento machista como beber alcohol, apostar dinero, fumar y gastar dinero en prostitutas u otras mujeres. Más aún, la conversión se traduce en que el ingreso del hombre es orientado hacia la familia o la educación de los hijos (Brusco, 1993). La relación entre machismo y pentecostalismo es un ejemplo de como un rasgo de la cultura latinoamericana ha sido modificado por el pentecostalismo. A través de la transformación del machismo, el pentecostalismo produce una adaptación local en un contexto particular. También se puede añadir una apropiación local de este movimiento en el cobijo que proporciona a personas situadas en vulnerabilidad a raíz de la expansión del neoliberalismo en la región. De igual modo, no se expande de manera homogénea por el subcontinente, sino que atendiendo a las particularidades locales; la existencia de distintas iglesias, muestra los distintos tipos de pentecostalismo. En síntesis, los anteriores son ejemplos de cómo este movimiento global tiene la habilidad de adaptarse a los contextos culturales. 


\section{Conclusiones}

A modo de conclusión podríamos señalar que, en el campo católico, el aggiomamento de la Iglesia Católica, a partir del Concilio Vaticano II, liberó tensiones que dieron como resultado diversas corrientes en una institución caracterizada por su universalidad. Tales tensiones, en efecto, tuvieron, entre otras cosas, un eje principal de conflicto que fue las distintas perspectivas en torno a la pobreza. Las condiciones propias de un continente subdesarrollado, con evidentes estructuras de atraso, llevaron a algunos sectores de católicos a enfrentarse a unas prácticas conservadoras de la Iglesia, la cual, desde la independencia, había estado vinculada con el Estado y las elites. Ello sumado al contexto de revolución existente en la década del sesenta y las conclusiones de la Segunda Conferencia Episcopal en Medellín-, generó la radicalización de grupos de católicos, los cuales decidieron encontrar a Jesús entre los pobres, impulsándolos a comprometerse a fondo con ellos y, en algunos casos, a una opción revolucionaria, expresado en el apoyo a movimientos sociales, partidos de izquierda e -incluso- sumarse a la lucha guerrillera como el caso de Camilo Torres.

Tal ha sido el caso, como hemos visto, de la teología de la liberación que cuestionaba el accionar de la iglesia, alejándose de la política de caridad de la iglesia, para encontrar a Jesús entre los pobres y — quizás no sería exagerarlo decirlo-, transformarse también en él. En contraposición a ello, los sectores conservadores-integristas y socialcristianos, en cierto modo, intentaron por todos los medios evitar la pluralización y politización de católicos. Para la perspectiva conservadora-integrista, en particular, la teología de la liberación se convertía en una verdadera amenaza para la identidad católica (identificada con el modelo eclesiológico de cristiandad). No obstante, hoy en día, la teología de la liberación ya no se considera una amenaza, como se veía en el pontificado de Juan Pablo II, sino que, en la actualidad, puede ser considerado una manera de mantener la hegemonía católica en un continente amenazado por las corrientes pentecostales.

Con respecto al pentecostalismo, se puede afirmar que su éxito en América Latina no se debe a que sólo sea una religión de los pobres, sino más 
bien que ha constituido una respuesta religiosa y con consecuencias prácticas en el comportamiento de los sujetos -como su erradicación del machismo- ante los cambios socioeconómicos. Más aún, constituye un movimiento que da respuesta a los procesos modernizadores, pero también a la globalización (como su adaptación local lo muestra). Finalmente, hay que identificar que ya no constituye, en un país como Chile, una religión de los grupos pobres solamente, sino que a consecuencia de cambios económicos, los pentecostales han accedido a la educación superior y mejores oportunidades laborales lo que implica una diferencia con las generaciones de la primera mitad del siglo XX. Es así como, desde la segunda mitad del siglo XX podemos ver en Chile a un movimiento con una composición social distinta y que en las generaciones jóvenes incluso se aprecia un cuestionamiento al modelo tradicional de autoridad.

\section{Referencias bibliográficas}

ADOFAME, Afe. 2010. "Pentecostal and Charismatic Movements in a Global Perspective". eN Turner, Bryan S. (ed.), The New Blackwell Companion to the Sociology of Religion. Malden, Oxford and Chichester: Wiley-Blackwell, pp. 498518, 2010.

AMORÓS, Mario. La Iglesia que nace del pueblo: Relevancia Histórica del Movimiento Cristianos por el Socialismo, en: Pinto, Julio (coord.). Cuando Hicimos Historia. La experiencia de la Unidad Popular. Santiago: Editorial LOM, 2005.

BEYER, Peter. "Religion and Globalization". En RITZER, George (ed.), The Blackwell Companion to Globalization. Malden, Oxford and Carlton: Blackwell, pp. 444-460, 2007.

BLANCARTE, Roberto. El pensamiento social de los católicos mexicanos. México DF: Fondo de Cultura Económica, 1996.

BRUSCO, Elizabeth. "The Reformation of Machismo: Asceticism and Masculinity among Colombian Evangelicals". En GARRAND.BURNETT, Virginia and Stoll, David (eds.) Rethinking Protestantism in Latin America. Philadelphia: Temple University Press), pp. 143-158, 1993.

BUSTAMANTE OLGUÍN, Fabián. "La construcción del enemigo en sus usos lingüísticos del integrismo católico en la justificación del golpe de Estado en Chile. El caso de las revistas Fiducia y Tizona, 1965-1973, Persona y Sociedad, Vol. XXVIII/N¹, enero-abril, 2014. 
"Historia local de una comunidad carismática católica durante la dictadura militar: Comunidad Dios con Nosotros, 1973-1983". Persona y sociedad, Vol. XXV, N³, 2011.

" "La formación de una nueva mentalidad religiosa de la élite empresarial durante la dictadura militar, 1974-1990. El catolicismo empresarial del Opus Dei”. Revista Cultura y Religión 4 (1): 7-20, 2010.

CASTRO GÓMEZ, Carlos. "La opción por los pobres: Análisis crítico de sus posibilidades y limitaciones en un mundo globalizado". En: ZALPA, Genaro y EGIL OFFERDAL, Hans (comp.), ¿El reino de Dios es de este mundo? El papel ambiguo de las religiones en su lucha contra la pobreza. Bogotá: CLACSO-Siglo del Hombre Editores, 2008.

CHERKASHIN, Viviana. Las comunidades de base en el régimen militar (1973-1989). Seminario de Tesis (Lic.) en Historia. Santiago: Facultad de Filosofía y Humanidades, departamento de Ciencias Históricas, Universidad de Chile, 2000 .

CHESNUT, R. Andrew. 2003. Competitive Spirits. Latin America's New Religious Economy. New York: Oxford University Press.

CLEARLY, Edward. "Latin American Pentecostalism". En DEMPSTER, Murray W., KLAUS, Byron D., PETERSEN, Douglas (eds.). The Globalization of Pentecostalism. A Religion Made to Travel. Oxford: Regnum, pp. 131-150, 1999.

CORTEN, André. "El establecimiento de una red de la Teología de la Liberación". En: BASTIAN, Jean Pierre (ed.). La modernidad religiosa: Europa latina y América Latina en perspectiva comparada. México DF: Fondo de Cultura Económica, 2004.

CUNNINGHAM, Lawrence. El catolicismo: una introducción. Madrid: Editorial AKAL, 2014.

DEL POZO, José. Historia de América Latina y del Caribe. Desde la Independencia hasta hoy. Santiago: LOM Ediciones, 2009.

DONOSO LOERO, María. Los Cristianos por el Socialismo en Chile. Santiago: Editorial Vaitea, 1975.

DROOGERS, André. "Paradoxical Views on a Paradoxical Religion: Models for the Explanation of Pentecostal Expansion in Brazil and Chile". En BOUDEWJNSE, Barbara; DROOGERS, André and KAMSTEEG, Frans (eds.). More than Opium. An Anthropological Approach to Latin American and Caribbean Pentecostal Praxis. Lanham, Maryland and London: The Scarecrow Press, pp. 1-34, 1998.

ESTRADA, Juan Antonio. El cristianismo en una sociedad laica: cuarenta años después del Concilio Vaticano II. Bilbao: Editorial Descleé de Brouwer, 2009. 
FEDIAKOVA, Evguenia. 2014. "Evangelicals in Democratic Chile: Clash of Generations?”. Social Compass, 61(1): 108-120.

FERNÁNDEZ, David. La Iglesia que resistió a Pinochet: historia, desde la fuente oral, del Chile que no puede olvidarse. Madrid: Editorial IEPALA, 1999.

FRESTON, Paul. "Pentecostalism in Latin America: Characteristics and Controversies". Social Compass, 45(3): 335-358, 1998.

GARCÉS, Mario y DE LA MAZA, Gonzalo. La explotación de las mayorias: protesta nacional, 1983-1984. Santiago: ECO-Comunicaciones, 1985.

JENKINS, Philip. The Next Christendom. The Coming of Global Christianity. New York: Oxford University Press, 2007.

KOURLIANDSKY, Jean Jacques. “América Latina, una persistente prioridad de la Santa Sede. Dossier Revista Vanguardia, número 48, julio-septiembre, 2013.

LALIVE D'EPINAY, Christian. Haven to the Masses: A Study of the Pentecostal Movement in Chile. London: Lutterworth Press, 1969.

LEHMANN, David. Struggle for the Spirit. Religious Transformation and Popular Culture in Brazil and Latin America. Cambridge: Polity Press, 1996.

LOAEZA, Soledad. "La iglesia Católica en la segunda mitad del siglo XX". En: PALACIOS, Marco y WEINBERG, Gregorio (dir.). Historia General de América Latina: América Latina desde 1930, Vol.VIII. París: UNESCO-Editorial Trotta, 2008.

MARTIN, Bernice. "From pre- to post Modernity in Latin Amercia: the case of Pentecostalism". En HEELAS, Paul (ed.). Religion, Modernity and Postmodernity. Oxford and Malden: Blackwell, pp. 102-146, 1998.

MÍGUEZ, Daniel. "Exploring the Argentinian case: Religious Motives in the Growth of Latin American Pentecostalism". En: SMITH, Christian and PROKOPY, Joshua (eds.). Latin American Religion in Motion. New York and London: Routledge, pp. 221-234, 1999.

MILLER, Donald y YAMAMORI, Tetsunao. Global Pentecostalism: The New Face of Christian Social Engagement. Berkeley: University of California Press, 2007.

ORELLANA, Felipe. "Fundamentalismo y pentecostalismo como expresión de religiosidades antagónicas: y un significativo lazo en común”, Polis, 11(32), 441-459, 2012.

PARKER, Cristián. Otra lógica en América. Religión popular y modernización capitalista. México DF: Fondo de Cultura Económica, 1993.

PATIÑO, Carlos. Guerras de religiones: transformaciones sociales en el siglo XXI. Bogotá: Siglo del Hombre Editores, 2006. 
PEREA, Francisco. El Papa en México: presencia y mensaje de Juan Pablo II. México DF: Editorial Diana, 1979, citado en BLANCARTE, Roberto. Historia de la Iglesia en México (1929-1982). México DF: Fondo de Cultura Económica, 1992.

ROBBINS, Joel. 2004. "The Globalization of Pentecostal and Charismatic Christianity”. Annual Review of Anthropology, 33: 117-143, 2004.

ROMERO, Javier y BUSTAMANTE OLGUÍN, Fabián. "Neoliberalismo poder y religión en Chile". Revista de Investigación Crítica (5): 79-100, 2016.

SALINAS, Maximiliano. Historia del Pueblo de Dios en Chile. La Evolución del Cristianismo desde la perspectiva de los pobres. Santiago: Editorial Rehue, 1987.

SLOOTWEG, Hanneke. "Pentecostal Women in Chile. A Case Study in Iquique”. En: BOUDEWIJNSE, Barbara; DROOGERS, André and

KAMSTEEG, Frans (eds.). More than Opium. An Anthropological Approach to Latin American and Caribbean Pentecostal Praxis. Lanham, Maryland and London: The Scarecrow Press, pp. 53-71, 1998.

WILKINSON, Michael. "What's Global about Global Pentecostalism?". Journal of Pentecostal Theology, 17: 96-109, 2008.

ZANOTTO, Gizele. "Tradición, familia y propiedad (TFP): un movimiento católico en Brasil (1960-1995)". Locus: Revista De História 16 (1). https://periodicos.ufjf.br/index.php/locus/article/view/20136. 